\title{
Configurações
}

Revista de sociologia

Violência e Criminalidade

\section{Francisco Louçã, João Teixeira Lopes e Jorge Costa (2014), Os burgueses: quem são, como vivem, como mandam. Lisboa: Bertrand Editora}

Fernando Bessa Ribeiro e Manuel Carlos Silva

\section{(2) OpenEdition \\ Journals}

Edição electrónica

URL: http://journals.openedition.org/configuracoes/2802

DOI: $10.4000 /$ configuracoes. 2802

ISSN: 2182-7419

Editora

Centro de Investigação em Ciências Sociais

\section{Edição impressa}

Data de publição: 18 dezembro 2015

Paginação: 131-135

ISBN: 1646-5075

ISSN: 1646-5075

Refêrencia eletrónica

Fernando Bessa Ribeiro e Manuel Carlos Silva, « Francisco Louçã, João Teixeira Lopes e Jorge Costa (2014), Os burgueses: quem são, como vivem, como mandam. Lisboa: Bertrand Editora », Configurações [Online], 16 | 2015, posto online no dia 29 dezembro 2015, consultado o 22 setembro 2020. URL : http://journals.openedition.org/configuracoes/2802 ; DOI : https://doi.org/10.4000/configuracoes. 2802 
Ribeiro, Fernando Bessa; Silva, Manuel Carlos - Francisco Louçã, João Teixeira Lopes e Jorge Costa (2014). Os Burgueses: quem são, como vivem, como mandam.

Configurações, vol. 16, 2015, pp. 131-135

\section{Francisco Louçã, João Teixeira Lopes e Jorge Costa (2014), Os burgueses: quem são, como vivem, como mandam. Lisboa: Bertrand Editora}

FERNANDO BESSA RIBEIRO*

Universidade do Minho

MANUEL CARLOS SILVA**

Universidade do Minho

Ao longo de mais de meio milhar de páginas, o leitor é confrontado com uma discussão aprofundada sobre a burguesia portuguesa: quem são, como vivem, como mandam, enfim, como se reproduzem social e politicamente. Apresentando um conceito da classe burguesa não fixista nem unidimensional, mas conjugando o marxismo com elementos de inspiração weberiana, os autores trabalham os mecanismos e formas de construção e reprodução das frações da classe burguesa em termos basicamente económicos, mas articulados com a dominação política e ideológica, evidenciando-se esta como uma classe organizada e mobilizada para a preservação de privilégios, rendas e lucros, assim como para a acumulação de capital em grande parte graças ao papel mediador e protetor do Estado ao seu serviço ao longo do tempo: desde a exploração colonial e agrícola, passando pela mediação comercial do import-export e do condicionamento industrial, até às rendas de monopólio (rendas fundiárias, privatizações, parcerias público-privadas, benefícios fiscais, fraude e evasão fiscais, transferências offshore, dívida pública). A imbricação e a promiscuidade dos interesses económicos com a política, nomeadamente nos cargos governamentais, ramificamse nas empresas e sectores-chave da economia, indo assim ao encontro, na esteira de Silva (2009), da tese weberiana e bourdieusiana da convertibilidade de recursos, passando os seus protagonistas do económico para o político e do político para o económico e financeiro.

Escrevendo os autores a partir de uma posição teórica e política claramente assumida de esquerda mas não dogmática, o livro permite-nos compreender as "artes" da burguesia, nomeadamente em Portugal, em dominar, cooptar, sobreviver e produzir consentimento pela força ideológica dos discursos dominantes e tornados lugares comuns e/ou senso comum veiculados pelos media e absorvidos e interiorizados por cidadãos despolitizados ou menos politizados e críticos.

\footnotetext{
* Doutorado, Universidade de Trás-os-Montes e Alto Douro e Centro Interdisciplinar de Ciências Sociais, polo Universidade do Minho. Email: fbessa@vodafone.pt.

* Doutorado, Centro Interdisciplinar de Ciências Sociais, polo Universidade do Minho. Email: mcsilva2008@gmail.com.
} 
Como bem se pode constatar em Costa et al. (2010), a grande burguesia não viu beliscados pela atual crise a sua posição social e seus privilégios. Não obstante os problemas que atingiram algumas das suas principais famílias, com destaque para a Espírito Santo, severamente atingida pelo colapso do BES, em momento algum a crise colocou em causa a sua hegemonia política e ideológica.

Muito mais há a dizer sobre o livro. Observando a história dos processos de constituição e reprodução da burguesia, talvez se justifique sublinhar que, ao contrário do que a ideologia dominante burguesa nos quer fazer crer, empresa e parentesco, capital e família são indissociáveis. Prosseguindo com a análise já empreendida em Os donos de Portugal, obra acima citada, os autores mostram-nos que a reprodução do capital não se faz à margem das relações familiares, não se podendo ver esta fusão entre propriedade e parentesco como um mero vestígio de estádios anteriores ao capitalismo, mesmo quando a formação social portuguesa apresente, no nosso entender, a imbricação do dominante modo de produção com outros modos de produção não capitalistas. Este é um mecanismo central da continuidade geracional, constituindo-se como um elemento decisivo para manter uma certa estabilidade da estrutura de classes, em especial dos grupos dominantes, no atual capitalismo. Assim, o estudo aprofundado do binómio economia-política, bem como do par empresaparentesco na sociedade portuguesa - que ora nos aparecem como fazendo parte de campos separados, ora como algo da esfera estrita da pequena empresa familiar, muito por força dos discursos meritocráticos da ideologia liberal e até de certa social-democracia -, é essencial para a compreensão das formas de reprodução social da grande burguesia e do controlo por ela exercido sobre a economia e a política. Se estudado a partir de um posicionamento crítico, tal permite interpelar e desfazer um dos pilares mais fortes da ideologia burguesia, o da meritocracia veiculada por teóricos estruturo-funcionalistas (cf. Parsons 1967; Davis e Moore, 1976), cujos propósitos políticos têm sido defendidos em todas as instâncias e por todas as formas, mormente pela economia, justamente designada por Pierre Bourdieu (2000: 11) como a ciência do Estado.

Formatados nas escolas de economia e gestão dominadas pela ortodoxia do pensamento teórico liberal, os mais novos, sobretudo os que, devido às disposições familiares, foram destinados para a seu tempo ocuparem o comando das empresas, incorporam com convicção os princípios económicos e, logo, políticos que servem cabalmente os seus interesses sociais, nomeadamente aqueles que são diretamente decorrentes da continuidade das suas empresas. Neste sentido, o livro permite evidenciar a aparente contradição entre os discursos de muitos dos membros destas famílias e as suas práticas. Defensores do liberalismo económico e da ideologia meritocrática - que, aplicada até às últimas consequências, deveria implicar a recusa da herança, isto é, da transmissão do património às gerações mais novas -, as suas práticas estão marcadas pela defesa de outros valores e capitais que escapam ao campo estritamente económico. Tal como 
referimos, uns e outros recursos são transferíveis e convertíveis entre si e, como tal, não podem ser separados. Por outras palavras, ao mesmo tempo que enaltecem o liberalismo económico nas empresas e no país, para si próprios colocam em prática sofisticados mecanismos, baseados no parentesco e em teias densas de relacionamento social, que mais não visam do que os preservar a si e às suas famílias dos efeitos destrutivos das lógicas mercantis.

A complexidade crescente dos negócios, combinada com a dificuldade de encontrar em cada nova geração os indivíduos com o perfil adequado à gestão de grandes grupos empresariais, pode forçar o recurso a gestores profissionais. Entram assim em cena os gestores, enquanto classe-apoio aliada da burguesia, referida pelos autores, aliás na esteira da distinção marxista e weberiana entre proprietários e gestores na nova fase do capitalismo. Não descartando que tal gera uma tensão evidente entre detentores do património e detentores da gestão, não deixa de ser certo que, mesmo nos casos em que a gestão está entregue a profissionais, a família não perde o controlo sobre aquilo que é efetivamente decisivo nos destinos da empresa: a sua viabilidade económica, a sua perenidade debaixo do controlo da família que a fundou. Obviamente, não se está perante uma exceção portuguesa, mas face à regra que prevalece em muitas empresas, incluindo algumas das maiores multinacionais, como é o caso, referindo apenas o setor automóvel, das famílias Quandt, na Alemanha, e Agnelli, em Itália, respetivamente principais acionistas da BMW e da FIAT. Ainda que a gestão destes grupos empresariais esteja nas mãos de gestores profissionais, tal não impede que a geração de turno no comando intervenha na gestão sempre que tal seja considerado necessário. Ou mesmo ter o controlo direto, como aconteceu com Ferdinand Piëch, neto do fundador da VW, primeiro responsável da empresa nos últimos 22 anos, até à sua demissão, em abril de 2015, em luta com o outro ramo da família, o Porsche.

Para a burguesia, as práticas de consumo ocupam um lugar fundamental no seu quotidiano. Através dela é organizada uma determinada estilização do modo de viver, de forma a tornar visível (e consolidar) a sua posição de classe, como nos revela de modo fascinante a segunda parte do livro, ao descrever e analisar os autofechados condomínios de luxo, as escolas que frequentam, as suas práticas de lazer e preferências de consumos conspícuos, servindo-nos do conceito de Veblen [1970 (1899)], amiúde presente no livro. Reconhece-se e compreende-se, pois, que à burguesia está associada uma cultura, ou seja, um conjunto de normas e práticas que condicionam e estruturam a existência dos seus membros e se exprimem em modos de comportamentos - comer, beber, vestir, lazer e outros - socialmente reconhecidos e reproduzíveis em qualquer contexto, quer esperado, quer imprevisto, como diria Pierre Bourdieu.

Compreendendo a burguesia, suas lógicas e modos de ação fora do quadro fechado e estreito da argumentação pretensamente meritocrática, celebrada pela ideologia dominante, os autores, aliás na esteira do que fizeram Francisco 
Louçã e José Castro Caldas em Economia(s), oferecem-nos um livro altamente desestabilizador. Questionando a burguesia como ela é, a obra inscreve-se claramente no trabalho de desconstrução do mundo como ele é, tendo em vista alargar as alternativas possíveis de onde sairá, se formos capazes de nos mobilizar através da ação coletiva organizada, uma outra sociedade, mais igualitária, mais justa e, porque não, mais fraterna e solidária, palavras hoje tão desprezadas pela burguesia, justamente porque elas são incompatíveis com o individualismo que organiza as nossas vidas e tudo corrói, replicando aqui a tese de Sennett (2001), aliás justamente citado pelos autores.

Aqui chegados, resta-nos lembrar que vezes sem conta a leitura deste livro poderoso e estimulante foi agitada pelo poema cantado por um dos maiores da música brasileira, Cazuza, infelizmente já não entre nós:

\author{
A burguesia não repara na dor \\ Da vendedora de chicletes \\ A burguesia só olha pra si \\ A burguesia só olha pra si \\ A burguesia é a direita, é a guerra \\ A burguesia fede \\ A burguesia quer ficar rica \\ Enquanto houver burguesia \\ Não vai haver poesia
}

Como certamente o poeta e cantor não deixaria de concordar, o confronto prossegue, hoje, em torno da austeridade e das políticas de saída para a crise. De um lado está o milhar de burgueses que dominam o país $(0,01 \%$ da população portuguesa), auxiliados pela classe-apoio aliada de gestores e administradores - composta, segundo os autores, por 300000 indivíduos (3,3\%), numa interpretação que assumem como mais restrita face a outras -; do outro, a esmagadora maioria dos que vivem do seu trabalho e não abdicam de lutar por uma outra vida, menos desigual e mais feliz. Permanece todavia um desafio para os autores, para os cientistas sociais e para os próprios cidadãos: porque é que os 96,69\% continuam subjugados a $3,31 \%$ ? Tal nos conduziria a questionar a velha tese economicista e reificada da "classe em si" e a necessidade de convocar uma perspetiva multidimensional de classe, já seminalmente avançada por Marx [1975 (1895)], nomeadamente a necessidade da organização e da ideologia/utopia ("a classe para si”) com base na articulação e aliança das classes exploradas, dominadas e subalternas. Os autores, embora tenham assinalado ao longo do texto mas não desenvolvido esta velha e nova questão teórica por não ser esse aliás o objetivo do livro, deram, do ponto de vista económico, sociológico e histórico, um excelente contributo histórico-empírico para um conhecimento aprofundado dos interesses económicos e financeiros da burguesia portuguesa, assim como das suas formas de exploração, dominação e distinção real e simbólica. 


\section{Bibliografia}

BOURDIEU, P. (2000), Les Structures sociales de l'économie. Paris: Seuil.

COSTA, L. F.; HONÓRIO, C.; LOUÇÃ, F. \& ROSAS, F. (2010), Os donos de Portugal: cem anos de poder económico (1910-2010). Porto: Afrontamento.

DAVIS, K. \& MOORE, W. [1976 (1945), "Algunos principios de estratificación”, in O. Velho et al. (orgs.), Estrutura de classes e estratificação social. Rio de Janeiro: Zahar Editores: 115-132.

MARX, K. [1975 (1895)], O 18 de Brumário de Louis Bonaparte. Coimbra: Centelha.

PARSONS, T. [1967 (1940)], "Una revisión analítica de la teoría de la estratificación social”, in Ensayos de teoría sociológica. Buenos Aires: Paidós: 333-378.

SENNET, R. (2001), A corrosão de carácter: as consequências pessoais do trabalho no novo capitalismo. Lisboa: Terramar.

SILVA, M. C. (2009), Classes sociais: condição objectiva, identidade e acção colectiva. Vila Nova de Famalicão: Húmus.

VEBLEN, T. [1970 (1899)], Théorie de la classe de loisir. Paris: Galimard. 